\title{
Convergence of the carbon intensity of the economies of the Asia-Pacific and non-OECD countries to the level of the OECD countries
}

\author{
Irina Filimonova ${ }^{1,2, *}$, Irina Provornaya ${ }^{1,2}$, Vasily $\mathrm{Nemov}^{1,2}$, Anna Komarova ${ }^{1,2}$ and \\ Yuri Dzyuba ${ }^{1}$ \\ ${ }^{1}$ Trofimuk Institute of Petroleum Geology and Geophysics of SB RAS, 630090 Novosibirsk, Russia \\ ${ }^{2}$ Novosibirsk State University, 630090 Novosibirsk, Russia
}

\begin{abstract}
The global goal of the world community is the transition to a "green" economy, characterized by rational use of electricity, reduction of harmful emissions, and consumption of renewable energy sources. The purpose of the research was to study the convergence of capacity emissions in developing countries to European countries' level. According to the results, countries striving for a lower emission intensity level to varying degrees. In non-OECD European countries, per capita income growth leads to a $0.26 \%$ reduction in emissions intensity. This fact means that economic growth creates additional resources that can be used to develop energyefficient technologies. In the post-Soviet space and the Asia-Pacific region, a significant effect on reducing emission intensity is provided by environmental policy's effectiveness to minimize carbon dioxide emissions.
\end{abstract}

\section{Introduction}

\subsection{The relevance of the research}

The global goal of the world community is the transition to a "green" economy, characterized by rational use of electricity, reduction of harmful emissions, and consumption of renewable energy sources. Achievement of this goal will allow regulating and significantly reducing carbon dioxide emissions. This gas causes an increase in average annual temperatures or warming of the climate, leading to the destruction of ecosystems and damage to economic activities in the affected areas. In 2019, the volume of emissions amounted to 34.2 billion tons and its number increased by $4.2 \%$ over the past five years. Maintaining a high growth rate may lead to negative consequences in the future.

Since the main reason for the increase in carbon dioxide emissions is the combustion of oil, coal, and natural gas, the energy complex principles are being transformed to regulate emissions. These principles include improving energy efficiency, developing renewable and nuclear energy, and replacing coal with natural gas. Improving energy efficiency implies using technologies to capture and process carbon dioxide, reduce energy losses during

${ }^{*}$ Corresponding author: FilimonovaIV@list.ru 
transmission, and introduce energy management and monitoring indicators that estimate emissions' content. One of these indicators is emission intensity (the ratio of carbon dioxide emissions to GDP). Therefore, the purpose of the research was to study the convergence of capacity emissions in developing countries to European countries' level, as one of the founders of environmental standards and international legislation in greening the economy.

\subsection{Literature review}

The idea of studying the convergence of developing countries to developed ones appeared after the analysis of neoclassical growth models in the 20th century. So, on their basis, two main concepts of convergence were identified: $\sigma$-convergence and $\beta$-convergence. They were presented in the papers of R. J. Barro and X. X. Salo-i-Martin [1, 2] at the end of the 20th century. The concept of $\sigma$-convergence implies that the studied indicator's spread in the considered countries decreases [3]. Experts use various indicators to check for this type of convergence: standard deviation, coefficient of variation, Theil index, Gini index and others, which estimate the distribution density. The $\beta$-convergence concept assumes that the indicator under consideration in countries where it is initially lower changes faster than in those where it is initially higher. Another popular convergence concept is the Distribution Dynamics method proposed in 1996 by the scientist D. T. Quah. This methodological approach involves modelling the studied indicator's distribution function to determine its stable state [4].

The aggravation of environmental problems caused by the increase in the number of greenhouse gases has justified the interest in a sustainable level of pollution. The first scientist was J. A. List, who in 1999, using unit root tests, verified the convergence of nitrogen oxide and sulfur dioxide emissions in the United States from 1929 to 1994. As a result of the study, convergence was found in all 10 United States regions, divided by the EPA classification [5].

Another work considering the convergence of carbon dioxide is the article "Energy consumption and $\mathrm{CO}_{2}$ emissions convergence in European Union member countries". For the research, the author uses the regression method and the distribution dynamics method. Within the regression method framework, the author estimates the equation of unconditional $\beta$ - convergence, and in the distribution dynamics method, the distribution functions of carbon dioxide emissions. The study found no convergence in 25 European countries from 1970 to 2010. The author explains this by the fact that hydrocarbon fuel plays a vital role in the region. It may also be related to differences in national policies, technology levels, and energy sector regulation [6].

The work "Post-Soviet Space and the European Union: Bridging the Energy Efficiency Gap" studied CIS countries' energy intensity. In the study, the post-Soviet space was divided into three clubs using a methodology developed by foreign scientists P. C. B. Phillips and D. Sul [7]. As a result of testing the models, the convergence of the clubs' energy intensity under consideration to the European level was found except Armenia, Moldova and the Russian Federation. The authors also found that the growth of per capita GDP strongly influences the decrease in energy intensity, and the degree of its decline in countries rich in natural resources (Russia, Kazakhstan) is lower than in the rest [8].

The article "Potential Economic Impact on Greenhouse Sight Emissions: Assessing Interregional Differentiation" analyzes GDP ratio to energy consumption and specific emissions using inequality coefficients such as the Gini index, Theil index and the Atkinson index. The article "Potential impact of the economy on $\mathrm{CO}_{2}$ emission: the estimation of interregional inequality" analyzes GDP ratio to energy consumption and specific emissions using inequality coefficients such as the Gini index, Theil index and the Atkinson index. The authors found that half of the regions have low energy productivity (unit of energy creates 
little added value). The study of carbon dioxide emissions also confirmed the high interregional differentiation caused by significant differences in the regions' income levels [9].

\section{Data and methodology}

One of the main goals of countries' energy policies worldwide is to reduce carbon dioxide emissions when burning traditional fuels. Developed countries strive to reduce emissions in absolute terms, while developing countries seek to reduce the specific amount of emissions $[9,10]$. Analysis of the dynamics of the ratio of carbon dioxide emissions to real GDP in various countries showed a steady decrease in the level of emission intensity of the economy and its stabilization at a certain level. In developing countries, specific emissions are higher than in European developed countries (Figure 1).

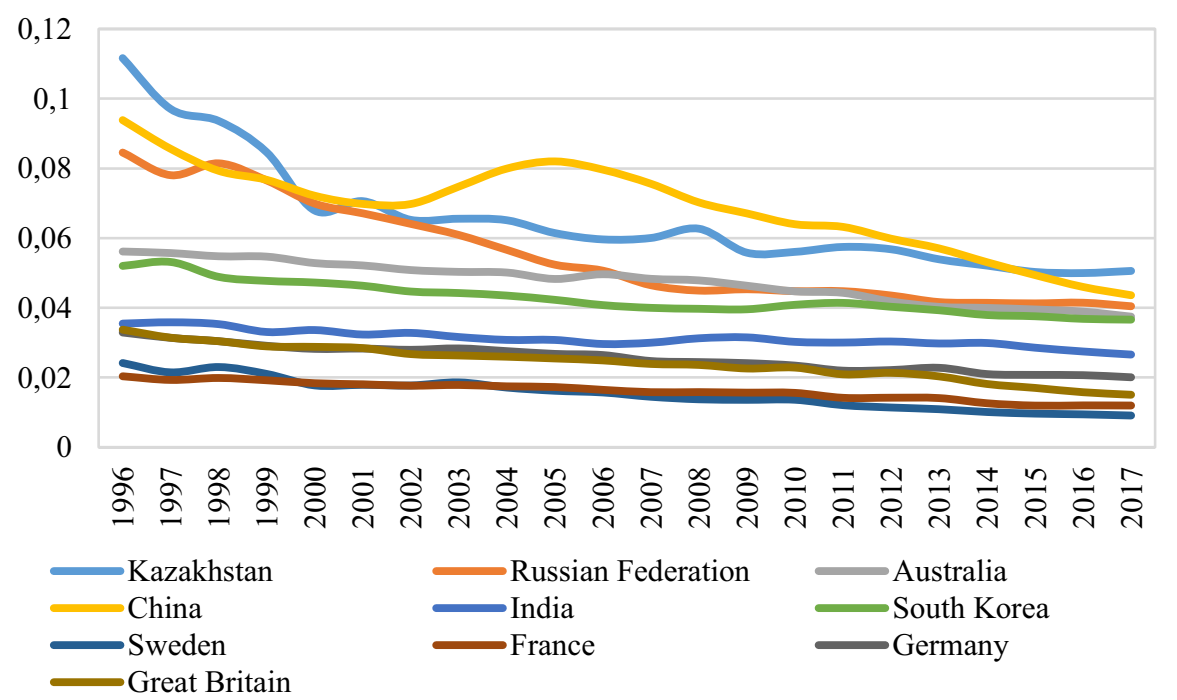

Fig. 1. The ratio of carbon dioxide emissions to real GDP in the countries of the world, \%

Moreover, over time, differences in emission levels decrease, i.e. there is an inevitable convergence of this indicator in macro-regions and across countries. This phenomenon has led to an interest in researching the convergence of emission intensity in developing countries to the European level. European countries are actively developing initiatives and implementing projects to improve the environment and develop renewable energy. At the moment, it is the developed countries of Europe that have a low level of emission intensity, while they have a strong economy, and their GDP is growing every year $[12,13]$.

The methodology presented in the article "Energy intensity in transition economies: Is there convergence towards the EU average" was chosen for our research [13]. Using this technique makes it possible to analyze the existence of convergence of emission intensity in developing countries to the European level. The methodology assumes that the current value of specific emissions $\varphi_{\text {it }}$ depends on the value in the previous period and on the expected value. However, it is not always possible to achieve the desired level, so the time lag parameter $\mu$ is introduced into the model: 


$$
\varphi_{\mathrm{it}}=\varphi_{\mathrm{i}, \mathrm{t}-1}\left(\frac{\varphi_{\mathrm{it}}^{*}}{\varphi_{\mathrm{i}, \mathrm{t}-1}}\right)^{\mu}
$$

According to the assumption of this methodology, developing countries are guided by the level in developed countries when choosing energy and environmental policies. Therefore, $\varphi^{*}$ it depends on the specific emissions in European countries $\varphi_{\mathrm{ut}}$ and on the level of income differences $\left(\mathrm{y}_{\mathrm{ut}}\right)$. For $\varphi_{\mathrm{ut}}$ we chose the average value for 10 European countries with the lowest specific carbon dioxide emissions. Accordingly, the expected specific carbon dioxide emissions can be described by the following formula:

$$
\varphi_{\mathrm{it}}^{*}=\mathrm{A}\left(\frac{\mathrm{y}_{\mathrm{ut}}}{\mathrm{y}_{\mathrm{it}}}\right)^{\eta} \varphi_{\mathrm{ut}}
$$

where A - a constant; $\eta$ - the elasticity of lagging GDP per capita.

By combining and logarithm both expressions, we bring the model to the following form:

$$
\ln \left(\frac{\varphi_{\mathrm{it}}}{\varphi_{\mathrm{i}, \mathrm{t}-1}}\right)=\mathrm{B}+\mathrm{D} \ln \left(\frac{\mathrm{y}_{\mathrm{ut}}}{\mathrm{y}_{\mathrm{it}}}\right)+\mathrm{C} \ln \left(\frac{\varphi_{\mathrm{ut}}}{\varphi_{\mathrm{i}, \mathrm{t}-1}}\right)
$$

where $\mathrm{B}=\mu \ln (\mathrm{A}) ; \mathrm{D}=\mu \eta ; \mathrm{C}=\mu$.

Thus, the dependent variable will be the growth of specific carbon dioxide emissions, and the independent variables are the level of income gap (ratio of GDP per capita) and the level of the gap in specific $\mathrm{CO}_{2}$ emissions of the European countries and the analyzed country. Factor $\mathrm{C}$ shows the rate of convergence of specific emissions in the considered country to the European level. If the coefficient $\mathrm{C}>0$, then the two variables' dynamics coincide, and there is convergence. Coefficient D is responsible for the impact of the wealth gap between countries, so its positive value indicates that convergence in income levels reduces specific emissions' growth.

An essential stage in the research is the formation of samples by countries. We formed the following groups to study the convergence of emission intensity to the European level: the countries of the post-Soviet space, the countries of the Asia-Pacific region and the countries of Europe that are not members of the OECD (Table1). The research is based on data from the World Bank and British Petroleum. Emissions intensity was calculated as the ratio of carbon dioxide emissions to real GDP in 2011 prices.

Table 1. Countries included in samples

\begin{tabular}{|c|c|c|}
\hline $\begin{array}{c}\text { European non-OECD } \\
\text { countries }\end{array}$ & $\begin{array}{c}\text { Countries of the post- } \\
\text { Soviet space }\end{array}$ & APR countries \\
\hline $\begin{array}{c}\text { Bulgaria, Cyprus, } \\
\text { Macedonia, Romania, } \\
\text { Slovenia, Turkey }\end{array}$ & $\begin{array}{c}\text { Kazakhstan, Batvia, } \\
\text { Lithuania, Russian } \\
\text { Federation, Uzbekistan, } \\
\text { Ukraine, Estonia }\end{array}$ & $\begin{array}{c}\text { Australia, China, India, } \\
\text { Indonesia, Japan, } \\
\text { Malaysia, New Zealand, } \\
\text { South Korea, Thailand }\end{array}$ \\
\hline
\end{tabular}

To determine the level of emission intensity of the economy, which could act as an asymptotic level in the study of convergence, a rating of 10 European countries was compiled with the lowest value of this indicator (Sweden, France, Ireland, Great Britain, Luxembourg, Spain, Germany, Portugal, Belgium, and Czech Republic). This group's average emission intensity was $0.018 \%$ and was used in calculations. 
The structure of energy consumption in the regions under consideration is similar to that in developed European countries, and they are also subject to general trends: a decrease in the share of coal, an increase in the use of natural gas and the development of alternative energy sources. The emission intensity in the considered regions decreases over time, but its level is higher than in European countries. This phenomenon is associated with the low availability of technologies and their high cost, increased dependence on hydrocarbons, and institutional barriers to developing renewable energy sources.

The formed samples of countries will be checked for $\sigma$-convergence, which will verify the convergence of emission intensity in the considered regions to European countries. To do this, we added the new object (conditional country) to the sample, the emission capacity of which is equal to the average European level. Then, for the extended group, we calculate the mean deviation and the Theil index. If the computed indicators decrease over time, then the existence of $\sigma$-convergence is confirmed. This analysis will also help select the appropriate time intervals when there was a convergence of emission capacities.

At the final stage, we will evaluate the regression coefficients built on the panel data and make appropriate tests to compare the models (Fischer, Breusch-Pagan and Hausman tests). Testing will select the most statistically significant model among fixed effects, random effects, and OLS regression.

\section{Results}

Before starting to determine the convergence of regions to the European level, it is necessary to determine $\sigma$-convergence to check the decrease in the studied indicator variation. To do this, we calculated the standard deviation and Theil index of specific carbon dioxide emissions in each sample, taking into account the average level in 10 European countries. This procedure will also allow us to correctly select the modeling period since the calculated indicators should decrease over several years. Figure 2 shows the standard deviation and Theil index dynamics for the post-Soviet countries, the Asia-Pacific region, and European non-OECD countries. Convergence was found in all regions: in the former Soviet republics, it arose in 2000, while in the APR and European countries - in 1996.

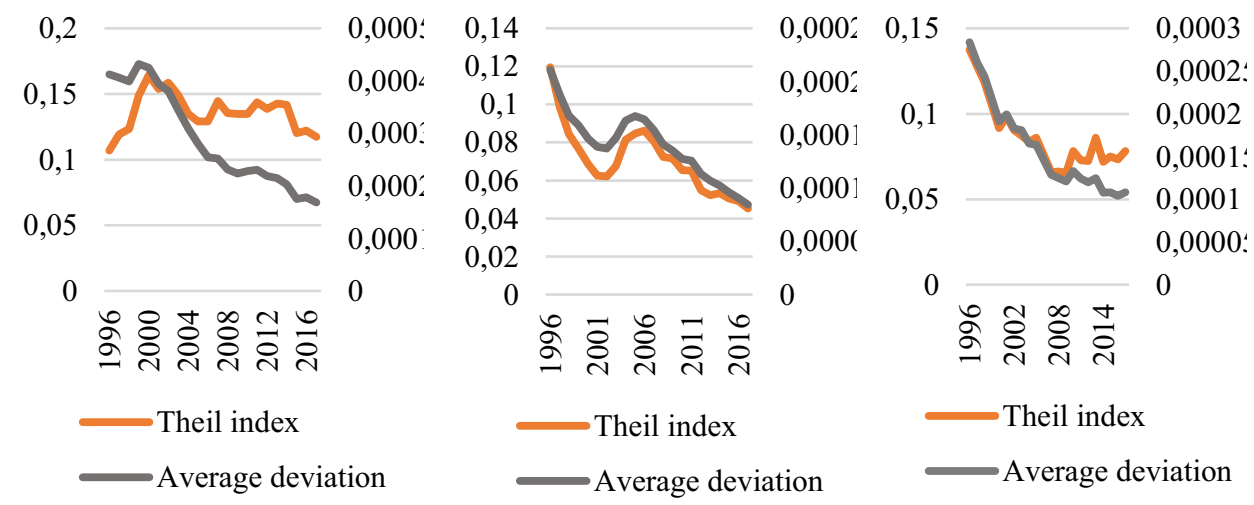
A) Countries of the post-Soviet
B) APR countries
C) European non-OECD space countries

Fig. 2. The presence of $\sigma$-convergence in macro-regions. 
The next step is to estimate the convergence model of specific carbon dioxide emissions for two regions and build three regression models to select the most statistically significant one using testing.

For the countries of the post-Soviet space, the following results were obtained (Table 2). The study used data from nine countries from 2000 to 2017. Statistical test results showed that a fixed-effects model should be used to analyze a region. Simple OLS-regression and random effects model were less-preferable according to the test results.

Table2. Fixed-effects model coefficients for post-Soviet countries.

\begin{tabular}{|c|c|}
\hline Indicator & Indicator value \\
\hline $\mathrm{D}$ & $0.039(0.277)$ \\
\hline $\mathrm{C}$ & $0.150(0.000)$ \\
\hline$\mu$ & 0.150 \\
\hline$\eta$ & 0.259 \\
\hline F-statistic & $9.568(0.000)$ \\
\hline Hausman test & 0.0003 \\
\hline $\mathrm{R}^{2}$ & 0.10 \\
\hline
\end{tabular}

The coefficients D and C turned out to be positive, which indicates the presence of convergence between 10 European countries and the countries of the post-Soviet space. Reducing the gap in the values of specific carbon dioxide emissions between European countries and the region under study by $1 \%$ leads to a decrease in this indicator's growth rate by $0.15 \%$. Besides, the convergence of the economies' welfare by $1 \%$ of the two regions will decrease the growth rate of specific emissions by $0.26 \%$.

We presented the research results of the convergence of specific carbon dioxide emissions in the APR countries in Table 3. Since $\sigma$-convergence was found in 1996, data from 15 countries were used for modeling during 1996-2017. Convergence to the European level was confirmed as all the equation's coefficients (C and D) were positive. The decrease in the growth rate of specific emissions is ensured in the APR countries due to the convergence of the regional economies and the ecological state's convergence. If the welfare gap between European countries and the Asia-Pacific countries is reduced by $1 \%$, then the growth rate of specific emissions will decrease by $0.008 \%$.

Table 3. Fixed-effects model coefficients for Asia-Pacific countries..

\begin{tabular}{|c|c|}
\hline Indicator & Indicator value \\
\hline $\mathrm{D}$ & $0.008(0.516)$ \\
\hline $\mathrm{C}$ & $0.124(0.000)$ \\
\hline$\mu$ & 0.124 \\
\hline$\eta$ & 0.065 \\
\hline F-statistic & $9.568(0.000)$ \\
\hline Hausman test & 0.000 \\
\hline $\mathrm{R}^{2}$ & 0.20 \\
\hline
\end{tabular}

In European countries, the convergence of the economy's emission intensity to the level of developed European countries was also found using panel regression with fixed effects, which, according to the test results, turned out to be the most statistically significant (Table 4). The coefficients $\mathrm{C}$ and $\mathrm{D}$ of the regression equation turned out to be positive, which confirms the region's specific emissions' convergence to the considered level. A decrease in the income gap with developed European countries leads to a decrease in the growth rate of emission intensity by $0.54 \%$, i.e. as the economy grows, the region becomes more energyefficient and environmentally friendly. The convergence in emission intensity with the 
developed countries of Europe causes a decrease in the growth of specific emissions of carbon dioxide by $0.16 \%$.

Table4. Fixed effects model coefficients for non-OECD European countries.

\begin{tabular}{|c|c|}
\hline Indicator & Indicator value \\
\hline $\mathrm{D}$ & $0.090(0.022)$ \\
\hline $\mathrm{C}$ & $0.166(0.000)$ \\
\hline$\mu$ & 0.166 \\
\hline$\eta$ & 0.542 \\
\hline F-statistic & $8.496(0.000)$ \\
\hline Hausman test & 0.001 \\
\hline $\mathrm{R}^{2}$ & 0.11 \\
\hline
\end{tabular}

Thus, estimates of the $\eta$ coefficients for the post-Soviet countries, European non-OECD countries, and the APR countries were $0.26,0.54$, and 0.06. It means that in non-OECD European countries, the European level convergence rate is higher than in other countries. Besides, the impact on the level of welfare has a more significant impact on reducing emission intensity in European countries. Besides, the welfare gap has a more significant impact on the emission reduction in Europe and the CIS. Besides, the welfare gap has a more significant impact on the emission reduction in Europe and the CIS. In the APR countries, the decrease in the value of specific emissions is faster than the reduction in the gap in GDP per capita. We can explain this because, in the APR countries, the demand for energy resources is initially higher than in the post-Soviet space countries. Therefore, green technologies and renewable energy sources lead to a more significant drop in emissions growth.

\section{Discussion}

Our research confirmed the existence of $\sigma$-convergence of the emission intensity level in the post-Soviet countries, Asia-Pacific countries and European countries that are not members of the OECD, with the ten most energy-efficient European countries. We expected this result since international activity in ecology and "green" energy has increased since the 90s of the 20th century. One of the most important reasons for reducing carbon dioxide emissions was the Kyoto Protocol, adopted in 1997 [14]. Thanks to this agreement, global warming has been popularized, and many countries have become more loyal to reducing carbon dioxide emissions. In 2015, the Paris Agreements were adopted, which set a new course for decarburizing the economy. It confirms countries' readiness to significantly reduce carbon dioxide emissions and transform the energy sector towards low-carbon development.

In contrast to the other regions under consideration, in the post-Soviet countries, rapprochement with the European level began in 2000. Experts explain this because the region's economy was going through the brutal collapse of the USSR, which caused a decline in production and the destruction of many economic ties. Also, the use of environmental technologies was not widely used at that time.

There was a divergence with the European level In the Asia-Pacific countries in 20022005 , caused by an increase in China's emission intensity. In the non-OECD countries of Europe, there was a convergence of emission capacities with the most energy-efficient European countries. The spread over time has decreased significantly, which is justified by strong economic and political ties too.

After testing the model for non-OECD European countries, we found that their emission intensity converges to the level of the ten most energy-efficient countries in Europe. Reducing the gap in the specific amount of carbon dioxide is influenced by the convergence of countries in terms of welfare and environmental development. The elasticity value $\eta$ is 
greater than the value of the coefficient $\mu$, which means that the convergence of incomes in the considered region and the ten most energy-efficient countries substantially impacts emission intensity convergence. Indeed, the introduction of abatement and clean-up technologies is costly, which hinders the implementation of various environmental policy measures. However, the country's income growth creates additional funds that can be used to improve the environment. With an increase in income, the population is more interested in environmental protection, seeks to reduce environmental pollution, develops ways to eliminate environmental problems, and becomes more loyal to environmental policy (introduction of quotas, taxes). The geographical proximity to the countries initiating international environmental projects makes the region rethink its ecology and energy policy and take the necessary measures promptly.

In the post-Soviet space countries, the convergence of energy development with European countries turned out to be significant, and the narrowing of the income gap was not significant. The same dependence can be traced in the countries of the Asia-Pacific region. We can explain it because international cooperation to combat climate change was actively developing, and countries were implementing policies to reduce emissions during the analyzed period. Real income in the post-Soviet space countries and the Asia-Pacific region increased from 1996 to 2017, but its gap with European countries persists significant. Moreover, the value in the income gap with the European region remains virtually unchanged during the analyzed period in some countries. Nevertheless, the considered countries of the post-Soviet space and the Asia-Pacific region did not stay away from combating pollution and reduced carbon dioxide emissions. Accordingly, environmental policy decisions and general awareness of climate change severity significantly influenced emissions reduction rather than increased welfare.

\section{Conclusion}

Widespread coverage of environmental issues forces governments to tighten legislation in environmental management and develop strategies to reduce pollution. One way to estimate pollution is to calculate emission intensity (the ratio of the amount of carbon dioxide to real GDP).

According to a study of the convergence of emissions, we found that countries striving for a lower emission intensity level to varying degrees. In non-OECD European countries, per capita income growth leads to a $0.26 \%$ reduction in emissions intensity. This fact means that economic growth creates additional resources that can be used to develop energyefficient technologies. In the post-Soviet space and the Asia-Pacific region, a significant effect on reducing emission intensity is provided by environmental policy's effectiveness to minimize carbon dioxide emissions.

Thus, the emission intensity of the regions under consideration tends to the European level, which is a consequence of international cooperation in ecology.

Acknowledgements: The work was supported by Scholarship of Russian Federation President for young scientists № СП-5871.2021.1 and the basic project of laboratory 1105 No. 0266-2019-0008.

\section{References}

1. R. J. Barro, Journal of Political Economy, 100, 223 (1992)

2. X. X. Sala-i-Martin, The Economic Journal 106, 1019 https://doi.org/10.2307/2235375

3. K.P. Glushchenko, J. New Economic Association, 4, 26 (2012) 
4. D. T. Quah, The Economic Journal, 106, 1045 (1996) https://doi.org/10.2307/2235377

5. J. A. List, Southern Economic Journal, 66(1), 144-155 (1999)

6. K. E. Kounetas, Energy Economics 69, 111-127 (2018)

7. P. C. B. Phillips, D. Sul, Econometrica 75, 1771 (2007)

8. O. A. Podkorytova and Yu. V. Raskina, St Petersburg University Journal of Economic Studies (SUJES), 2, 106-122 (2014)

9. I. A. Zabelina and E. A. Klevakina, Bulletin of Zabaikalsky State University, 12, 124$132(2013)$

10. L. Eder, I. Filimonova, V. Nemov, A. Komarova, and K. Sablin, E3S Web Conf. 80, 03010 (2019)

11. I. Filimonova, A. Komarova, and M. Mishenin, Oeconomia Copernicana, 11(2), 309324 (2020)

12. L. V. Eder, I. V. Provornaya, I. V. Filimonova, V. D. Kozhevin, and A. V. Komarova, Energy Procedia 153, 112-117 (2018)

13. L. V. Eder, I. V. Provornaya, and I. V. Filimonova, Geogr. Nat. Resour. 40, 9-14 (2019)

14. A. Markandya, S. Pedroso-Galinato, and D. Streimikiene, Energy Economics, 28(1), 121-145 (2006)

15. A. A. Akaev, Bul. RAS, 87(7), 587-598 (2017) 